\section{Increasing use of stimulants warns of potential abuse}

SIR - Your Editorial 'Defining natural' (Nature 452, 665-666; 2008) indicates that cognitiveenhancing drugs have only mild effects similar to caffeine, and the News story 'Poll results: look who's doping' (Nature 452, 674-675; 2008) highlights the general increase in their availability through Internet purchase and possibly diversion of prescriptions. By far the most frequently prescribed of these drugs - the stimulant medications amphetamine and methylphenidate - have abuse potential and therefore warrant particular concern.

The World Health

Organization (WHO) tracks by country the yearly production, supply and consumption of psychotropic substances, including stimulant drugs. The most recent figures suggest that we should evaluate carefully whether diversion of methylphenidate and amphetamine may be increasing in the United States. From 1995 to 2006, consumption estimates by the $\mathrm{WHO}$ and prescriptions recorded by the healthcare-information company Verispan both increased linearly. Moreover, the $268.9 \%$ relative increase in the WHO estimates of consumption, from 4.66 to 17.9 defined daily doses per 1,000 population, far exceeded the relative increase in number of prescriptions per year, from $15,044,359$ to $30,137,136$ (100.3\%).

The greater increase in consumption could be related to a shift in the age of individuals treated for attention-deficit hyperactivity disorder, as more adults are now seeking diagnosis and treatment. This could influence debate over whether some prescriptions for clinical treatment of adults are being appropriated instead for performance enhancement or recreational purposes. History teaches us that either of these could escalate into misuse.

We have serious concerns about the dramatic increase in national consumption and the smaller, but still large, increase in annual prescriptions of stimulant medications. These rises should make us vigilant to avoid a potential repeat of past episodes of abuse.

James M. Swanson University of California, Irvine, Department of Pediatrics, Child Development Center, 19722 MacArthur Boulevard, Irvine, California 92612, USA

Nora D. Volkow National Institute on Drug Abuse, 6001 Executive Blvd, Room 5274, Bethesda, Maryland 20892, USA

\section{Costa Rica's biotech project still on track for end of year}

SIR - In your News story

'Costa Rican biotech centre in peril' (Nature 452, 787; 2008),

you claim that the European

Union (EU) is threatening

to withdraw its contribution to the National Centre for Biotechnological Innovation (CENIBiot) project. We would like to clarify that the project is going ahead - we have not requested an extension of the EU's deadline, nor has the EU refused to grant one.

We are currently receiving sealed bids to remodel the CENIBiot building and equipment. All funds will be used before 5 December this year, as required under the EU agreement. No appeals are permitted for failed bids. Objections are dealt with according to EU procedure, without delaying application of the contract - unless a clear irregularity arises during the process, in which case it is referred to the EU. We have made every effort to guarantee maximum transparency in the process and to prevent violations.

For each bid, a tribunal of independent technical evaluators is appointed (the identity of the evaluators is kept confidential), along with a president and secretary for the evaluating committee. Representatives from the EU, the Ministry of Foreign Relations and the Ministry of Science and Technology attend as observers to reinforce the transparency of the process.

The Strategic Development Unit of CENIBiot is preparing contracts for economic study packages, updating biotechnological databases in Costa Rica and organizing visibility contracts and the exchange of experience and capabilities.

All this information is available from the ministry, is in accordance with the 2008 operation plan of the project and is paving the way for the identification of CENIBiot demonstration projects, on which we are now working.

Antonieta Corrales Communication Office, Ministry of Science and Technology, Costa Rica

\section{A prime problem that even quantum computing can't solve}

SIR - Your News Feature 'The dreamweaver's abacus' (Nature 452, 803-805; 2008) seems to have been rather carried away by the exciting prospects on offer from the emergent techniques of quantum computing. One thing that even quantum computing can never accomplish is "factoring large prime numbers". It cannot even factor small ones.

The author is in august company, however, as no less a personage than Bill Gates has had similar visions. In connection with the need to break modern encryption, he wrote: "The obvious mathematical breakthrough would be development of an easy way to factor large prime numbers" (in The Road Ahead; Viking Press, New York, 1995).

Robert P. Bywater Magdalen College, High Street, Oxford OX14AU, UK

\section{Analyses support theory of stochastic regulation of fisheries}

SIR - The month that saw the passing of David Cushing, perhaps Britain's leading marine fisheries ecologist, also saw evidence in Nature for his little-known theory of stochastic regulation of fish stocks.

Coilín Minto and his colleagues show that both the survival and variability of fish larvae increases as the size of the population declines to give a densitydependent regulation (C. Minto, R. A. Myers and W. Blanchard Nature 452, 344-347; 2008). Christian Anderson and his co-workers further explain how changes in the demographics of populations can generate these effects, which are magnified by fishing (C. N. K. Anderson et al. Nature 452, 835-839; 2008).

Almost 20 years ago, Cushing and John Shepherd speculated that increased variability in larval survival provides the strong regulation that allows intensive fishing, and demonstrated the effects through modelling (J. G. Shepherd and D. H. Cushing Phil. Trans. R. Soc. Lond. B 330, 151-164; 1990).

At the time, the hypothesis was left as plausible, likely even, but unresolved, as examinations of data proved inconclusive. The recent metadata analyses in Nature provide support for more variability when the population is small and so confirm at least a role for stochastic regulation in fish stocks. The analyses also reveal little or no clear increase in variability in many fish stocks, including many cod stocks. Other regulatory mechanisms might also exist.

Joe Horwood Centre for Environment, Fisheries \& Aquaculture Science, Department for Environment, Food and Rural Affairs, Lowestoft, NR33 OHT, UK John Shepherd School of Ocean and Earth Science, National Oceanography Centre, University of Southampton, SO14 3ZH, UK 